\title{
CORRIGENDUM
}

\section{Early, sustained efficacy of adeno-associated virus vector-mediated gene therapy in glycogen storage disease type la}

DD Koeberl, BD Sun, TV Damodaran, T Brown, DS Millington, DK Benjamin Jr, A Bird, A Schneider, S Hillman, M Jackson, RM Beaty and YT Chen

Gene Therapy (2006) 13, 1430. doi:10.1038/sj.gt.3302857

Correction to: Gene Therapy (2006) 13, 1281-1289. doi: $10.1038 /$ sj.gt.3302774

Since the publication of the above issue, the authors have noticed that they have missed the following sentence from the Acknowledgements section. The sentence is shown below:

G6Pase-KO mice were provided by Dr Janice Chou at the National Institutes of Health.

The authors would like to apologise for this mistake. 